\title{
Ankylosing spondylitis in North India: a clinical and immunogenetic study
}

\author{
SANJEEV PRAKASH, NARINDER K. MEHRA, SNEH BHARGAVA, \\ MAHESH C. VAIDYA, AND ANAND N. MALAVIYA
}

From the All India Institute of Medical Sciences, New Delhi - 110 029, India

SUMMARY Fifty-one North Indian patients with ankylosing spondylitis (AS) are described with mean age of onset $21 \cdot 2$ years and male to female ratio of $16: 1$. AS began with peripheral arthritis in $47 \%$, low back pain in $41 \%$, acute anterior uveit is in $10 \%$, and heel pain in $2 \%$ of the patients. $76 \%$ of 51 patients had one of the extra-axial features of AS: peripheral arthritis $(61 \%)$, heel pain $(24 \%)$, anterior uveitis $(22 \%)$, urethritis $(12 \%)$, kidney disease $(10 \%)$, mucosal ulcerations $(6 \%)$, aortic incompetence (4\%), and apical pulmonary fibrosis (4\%). A majority (71\%) of the patients with peripheral arthritis had mono- or oligoarthritis affecting mainly the lower limb joints. Two patients had coexistent rheumatoid arthritis also. HLA-B27 antigen was detected in $48(94 \%)$ of 51 patients compared with $7(6 \%)$ of 118 controls (relative risk 254; Fisher's exact $p=3 \cdot 49^{-29}$ ). On comparing patients with juvenile onset AS and patients with adult onset disease we found peripheral arthritis to be more frequent at the beginning and during the course of disease in the former.

Ankylosing spondylitis (AS) of the primary variety or that associated with Reiter's disease, psoriasis, and inflammatory bowel disease shows a high degree of association with HLA-B27 antigen in all races studied. ${ }^{12}$ Not only that, the prevalence of AS in a population is directly related to the frequency of HLA-B27 antigen. Thus at one extreme are the male Haida Indians, $50 \%$ of whom carry HLA-B27 and $6 \%$ have AS, and at the other are African blacks and Australian aboriginals, in whom both HLA-B27 and AS are extremely rare. ${ }^{23}$ The frequency of HLA-B27 in the North Indian population is $6 \%,{ }^{4}$ similar to that in Caucasians. ${ }^{12}$ The prevalence of AS in Caucasians is $0.1 \% .^{3}$ If the prevalence is the same, there would be more than 0.6 million patients with AS in India with a population of 680 million. Yet there are no thorough reports on the clinical, immunological, and immunogenetic aspects of this disease from India. In fact not much attention has been paid to this chronic, crippling disorder in India. For the last few years our laboratory has been engaged in the sytemetic study of HLA-B27 related arthropathies. ${ }^{4-7}$ In this report we describe 51 cases of definite primary ankylosing

\section{Accepted for publication 3 August 1983.}

Correspondence to A. N. Malaviya, MD, Division of Clinical Immunology, Department of Medicine, All India Institute of Medical Sciences, New Delhi - 110 029, India. spondylitis seen prospectively over a 2-year period at the immunology clinic of our institute.

\section{Materials and methods}

Consecutive unrelated patients of North Indian stock attending the immunology clinic of the All India Institute of Medical Sciences, New Delhi, were studied. All of them were seen by 2 of the authors (A.N.M. and S.P.) and questioned in detail about the joint symptoms, heel pain, symptoms of acute anterior uveitis (AAU), conjunctivitis, urethritis, inflammatory bowel disease, and mucosal and skin lesions. Any past and family history of these disorders was also recorded and wherever possible the affected relatives were examined. A thorough physical examination was done with special attention to the joints, spine, eyes, skin, buccal mucosa, genitalia, chest, and cardiovascular systems.

Tests for rheumatoid factor by the standard latex agglutination test (Rheuma-Welcotest kit, Burroughs-Wellcome, UK); posteroanterior and $15^{\circ}$ oblique view roentgenograms of the sacroiliac joints; and tissue typing by the National Institute of Health (NIH) 2-stage microlymphocytotoxicity test ${ }^{*}$ was done on all the patients. Controls for tissue typing were 118 unrelated healthy volunteers of North Indian stock. 


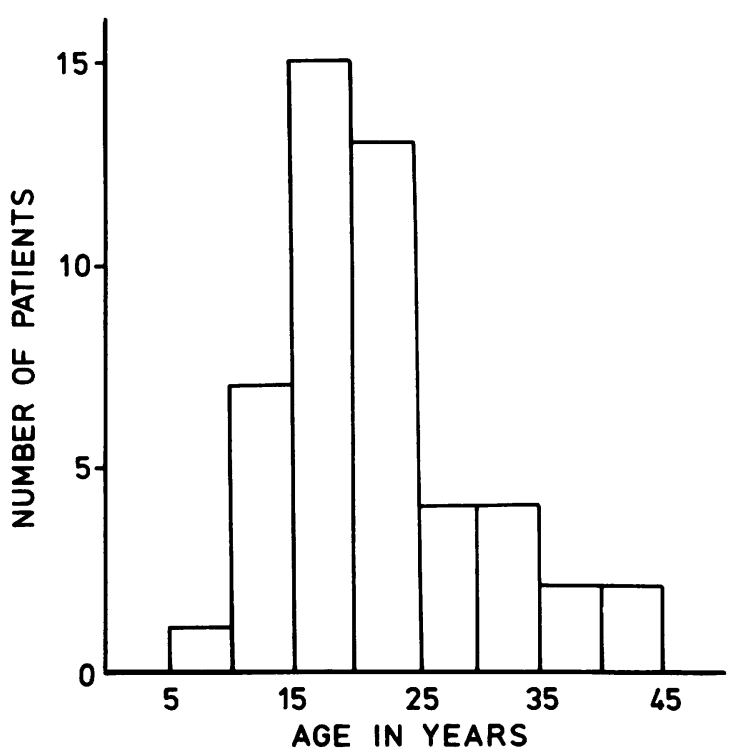

Fig. 1 Age of onset in 51 patients with ankylosing spondylitis.

The radiographic changes of sacroiliitis were graded from I to III as follows:

Grade I. Loss of clear-cut corticate joint margins with subchondral erosions and apparent widening of joint space.

Grade II. Sclerosis of varying degrees and extent along the joint margins and narrowing of the joint space.

Grade III. Obliteration of the joint space with osseous fusion.

The $x$-rays were graded by a radiologist (S.B.) experienced in reading sacroiliac films. The diagnosis of ankylosing spondylitis was made according to the Rome criteria ${ }^{9}$ but only in patients with radiographic sacroiliitis grade II or III. Reiter's disease, psoriasis, and inflammatory bowel disease were excluded. Anterior uveitis was diagnosed either by slit-lamp examination or in the presence of its sequelae. Arthritis was considered when joints were tender and/or swollen, and the mean degree of asymmetry of peripheral arthritis was calculated as the proportion of joints involved asymmetrically. ${ }^{10}$

\section{Results}

Of 613 patients seen in the clinic during 2 years 133 had various spondyloarthropathies, of which 51 could be diagnosed as ankylosing spondylitis- 48 men and 3 women (M:F=16:1). The mean age of onset of ankylosing spondylitis was $21 \cdot 2$ years (range 5 to 44 years), and in 16 of 51 patients the disease started before the age of 17 years (Fig. 1). The duration of symptoms in our patients varied from 4 months to 40 years, average 8.7 years (Table 1 ).

The commonest mode of onset of AS was peripheral arthritis-in $47 \%$ of patients; it was followed by low back or buttock symptoms $(41 \%)$, anterior uveitis $(10 \%)$, and heel pain in $2 \%$. Thirtynine (76.5\%) patients had one or other extra-axial features of ankylosing spondylitis (Fig. 2). Thirty-one (61\%) had peripheral arthritis of which four had acute anterior uveitis (AAU), three suffered from kidney disease and one from aortic incompetence in addition. Of the remaining 20 patients 6 had AAU, one suffered fiom both AAU and glomerulonephritis and another from aortic incompetence and glomerulonephritis. The mean duration of AS was 5.8 years in 12 patients with only spinal disease compared with 9.6 years in 39 patients with extraaxial disease also.

$X$-ray changes of sacroiliitis grade II or III were present in all the patients (by definition) and were bilaterally symmetrical in all except one patient. Twenty-seven (53\%) patients had grade II and 24 $(47 \%)$ had grade III $x$-ray changes, and the severity of these changes correlated well with the duration of disease (Table 1). Though radiographs of lumbar spine were not available in all the patients, clinically completely rigid spine and kyphosis were seen more frequently in patients with longstanding disease (Table 1).

Twenty-four $(47 \%)$ of patients had peripheral joint involvement at the beginning of the disease,

Table 1 Severity of ankylosing spondilitis and duration of disease (in years) in 51 patients

\begin{tabular}{lcccc}
\hline & $\begin{array}{l}5 \text { years, } \\
\text { no. }(\%)\end{array}$ & $\begin{array}{l}5-9 \text { years, } \\
\text { no. (\%) }\end{array}$ & $\begin{array}{l}\text { 10-19 years, } \\
\text { no. (\%) }\end{array}$ & $\begin{array}{l}\text { Total no. } \\
\text { no. (\%) }\end{array}$ \\
\hline $\begin{array}{l}\text { Number } \\
\text { Radiographic sacroiliitis }\end{array}$ & 20 & 12 & 15 & 4 \\
$\quad \begin{array}{l}\text { Grade II } \\
\text { Grade III }\end{array}$ & $17(85)$ & $7(58)$ & $3(20)$ & 0 \\
Rigid spine & $3(15)$ & $5(42)$ & $12(80)$ & $4(100)$ \\
$\begin{array}{l}\text { Kyphosis } \\
\text { Acute anterior uveitis (AAU) }\end{array}$ & $5(25)$ & $7(58)$ & $11(73)$ & $4(100)$ \\
\hline
\end{tabular}




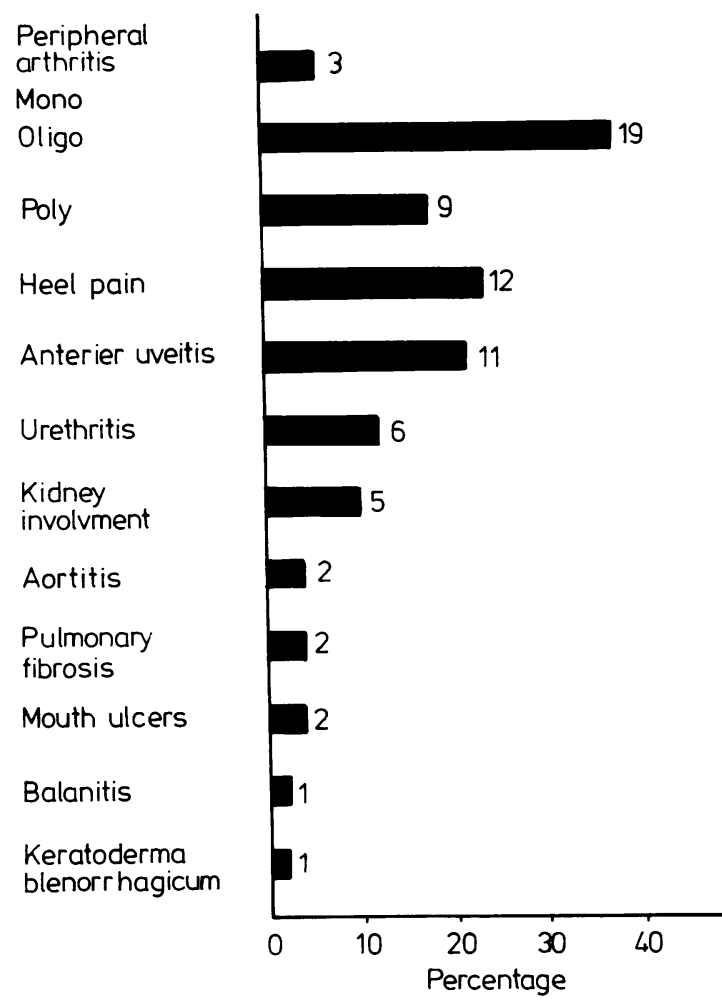

Fig. 2 Clinical manifestations in 51 patients with ankylosing spondylitis.

mainly of lower limb joints (Table 2 and Fig. 3). The average number of joints affected in them at the onset was $1 \cdot 8$ (range $1-4$ joints), and often they were involved asymmetrically (mean degree of asymmetry $=0 \cdot 49$ ). During the course of the disease 31 $(61 \%)$ patients developed peripheral arthritis, and the average number of joints affected was also increased to 5.9 (range 1-39 joints), though the majority of patients had mono- or oligoarthritis (Fig. 2).

Table 2 Distribution of peripheral arthritis in patients with ankylosing spondylitis

\begin{tabular}{|c|c|c|c|c|}
\hline & \multicolumn{2}{|c|}{$\begin{array}{l}\text { At onset } \\
(n=24)\end{array}$} & \multicolumn{2}{|c|}{$\begin{array}{l}\text { During the } \\
\text { course of } \\
\text { disease }(n=31)\end{array}$} \\
\hline & No. & $(\%)$ & No. & $(\%)$ \\
\hline Only upper limbs & 2 & $8 \cdot 3$ & 2 & $6 \cdot 4$ \\
\hline Only lower limbs & 22 & $91 \cdot 7$ & 19 & $61 \cdot 3$ \\
\hline $\begin{array}{l}\text { Both upper and } \\
\text { lower limbs }\end{array}$ & 0 & 0 & 10 & $32 \cdot 3$ \\
\hline
\end{tabular}

Joints of lower extremity were most commonly affected (Table 2, Fig. 3). The mean degree of asymmetry of peripheral arthritis was $0 \cdot 28$. Heel pain was a prominent symptom in 12 patients - unilateral in 4 and bilateral in 8 . Ten of these 12 patients had peripheral arthritis also.

Ankylosing spondylitis started with AAU in 5 patients, and 3 of them developed spinal disease within 2-4 years, while in the other 2 it occurred 15 and 25 years later respectively. During the course of their disease 11 patients suffered from AAU, 7 in one eye and 4 in both eyes. The 2 eyes were affected at

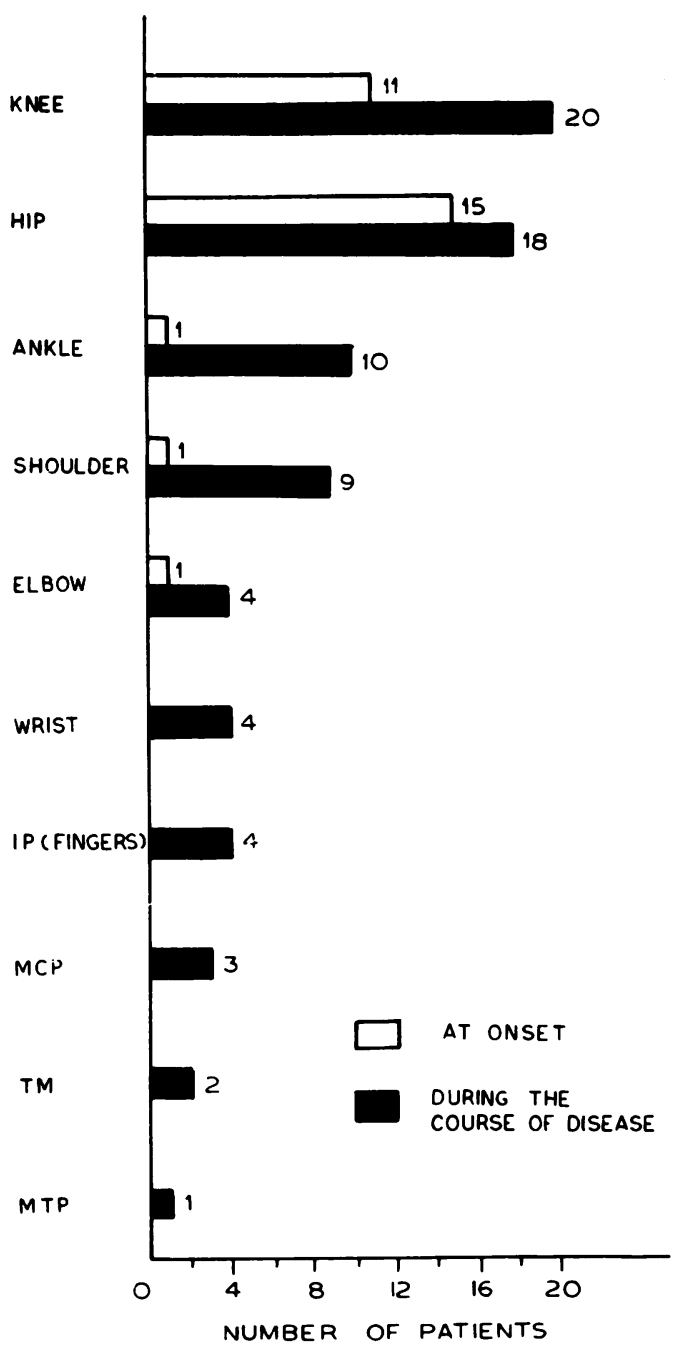

Fig. 3 Peripheral joints involved at the onset (24 patients) and during the course (31 patients) of ankylosing spondylitis. $I P=$ interphalangeal. $M C P=$ metacarpophalangeal. $T M=$ temperomandibular. $M T P=$ metatarsophalangeal . 
different times in 3 of the four patients with bilateral AAU. Four patients had recurrent episodes of uveitis. There was correlation between the duration of dise ase and AAU (Table 1). AAU occurred in 7 of 20 patients without peripheral arthritis and 4 of the 31 patients with peripheral arthritis, and this difference was statistically not significant $(p>0.05)$.

Aortic incompetence was observed in 2 patients with disease of 5 and 14 years' duration respectively. One of them had peripheral arthritis also, and the other had mesangioproliferative glomerulonephritis.

Four patients were found to have proteinuria, and kidney biopsies from them revealed mesangioproliferative glomerulonephritis in 2 , proliferative glomerulonephritis in one, and minimal change glomerulonephritis in another. One more patient had chronic renal failure, and a kidney biopsy was not done on him.

There was one female patient with keratoderma blenorrhagicum without any other feature of Reiter's disease. Other manifestations of ankylosing spondylitis in our patients included urethritis $(12 \%)$, apical pulmonary fibrosis $(4 \%)$, and recurrent painless superficial ulcerations of buccal mucosa $(2 \%)$ and genitalia $(2 \%)$. Since urethritis and mucosal ulcerations occurred mainly after sacroiliitis was established, it was difficult to diagnose Reiter's disease in such cases.

Six $(12 \%)$ of our 51 patients had another close relative suffering from AS: brothers of 3 patients, brother and grandfather of one, maternal uncle of one and mother and maternal uncle of another patient. One male patient's daughter suffered from Reiter's disease.

Tests for rheumatoid factor were negative in sera of all except 2 patients who gave a positive test with a titre of 1:160 and both of them had severe, symmetrical, deforming arthritis of small and large joints of all the extremities with complete ankylosis of the spine. They probably had coexistent AS and rheumatoid arthritis.

HLA-B27 antigen was detected in $48(94 \%)$ of 51 patients compared with $7(6 \%)$ of 118 control subjects, giving a relative risk of 254 (corrected Fisher's exact text, $p=3 \cdot 49^{-29}$. None of the other A or B locus antigens deviated significantly in patients with AS, though relative risks were slightly high for AW23 (2.7), A25 (2.7), and AW33 (2.7). HLA-A2 was present in $29 \%$ of 51 patients and $28 \%$ of 118 controls. Except for HLA-BW41 all other B locus antigens were diminished in frequencies among patients. HLA-BW41 was present in $2 \%$ of patients and $1.7 \%$ of controls (relative risk 1.32). The frequencies of HLA-B7 and B8 were decreased out of proportion to the reduction in frequencies of other $B$ locus antigens; still the sum of reciprocals of their relative risks
$(1 / 0 \cdot 16+1 / 0 \cdot 17=12)$ was a fraction of relative risk for HLA-B27.

A comparison of the clinical manifestations of AS in 16 juvenile onset patients (less than 17 years) and 35 adult onset patients revealed that the disease began in the peripheral joints in $81 \%$ of juvenile onset patients compared with $31 \%$ of adult onset patients (Fisher's exact text, $p=0.001$ ) and $87 \%$ of former had it during the course of disease compared with $48 \%$ of the latter group (Fisher's exact text, $\mathrm{p}=0 \cdot 008)$.

\section{Discussion}

The findings of the present study indicate that the clinical and the HLA profile of ankylosing spondylitis in North India is generally similar to that reported from the west. ${ }^{11-13}$ (The North Indian stock is Caucasian, while the South Indian is primarily Dravidian. We have not yet studied HLA in Madras). Thus it is primarily a disease of the young males, with the peak onset in the second decade, when the brunt of the disease is on the spine. But peripheral joints characteristically mono- or oligoarthritis of large joints of lower limbs - are also affected in addition to the Achilles tendon, uveal tract, kidney, and cardiovascular systems. However, a few minor differences were noted. The onset of AS with peripheral arthritis was almost as frequent as with low back symptoms, and this could be due to the fact that the present study included a higher proportion $(31 \%)$ of juvenile onset AS patients, in whom the disease usually starts in the peripheral joints. ${ }^{14}{ }^{15}$ And the earlier onset of the disorder in our patients may be because the exposure to the environmental agents occurs at a younger age. Now that the enteric organisms are being implicated in the causation of $\mathrm{AS},{ }^{16}$ the chances of infections with microbes like Klebsiella occurring early in life are high in India, where gut infections are prevalent. On the other hand the possibility that many of our patients with peripheral arthritis and sacroiliitis may have started as Reiter's disease but might have forgotten the mild urethritis or conjunctivitis cannot be ruled out. Reiter's disease is not uncommon in India. ${ }^{7}$

Another unexpected and surprising observation was the high incidence $(10 \%)$ of renal involvement in our patients with AS, and the commonest kidney lesion seen was glomerulonephritis and not amyloidosis as has been reported ${ }^{17}$. A high incidence of glomerulonephritis has been noted not only in AS but also in other HLA-B27 related arthropathies occurring in India ${ }^{6718}$ This observation and the finding of hypergammaglobulinaemia and circulating immune complexes in sera of a large proportion of 
patients with $\mathrm{AS}^{19}{ }^{20}$ would suggest that ankylosing spondylitis is immunoinflammatory in nature.

The authors thank Miss Vena Taneja for her help in tissue typing.

\section{References}

1 Brewerton D A. HLA-B27 and the inheritance of susceptibility to rheumatic diseases. Arthritis Rheum 1976; 19: 656-68.

2 Masi A T, Medsger T A. A new look at the epidemiology of ankylosing spondylitis and related syndromes. Clin Orthop 1979; 143: 15-29.

3 Masi A T. Epidemiology of B27-associated diseases. Ann Rheum Dis 1979; 38 (suppl 1): 131-4.

4 Mehra N K, Prakash S, Vaidya M C, Malaviya A N. Ankylosing spondylitis, Reiter's disease and other HLA-B27 related arthropathies in North India. In: Dawkins R L, Christiansen F T, Zilko P J, eds. Immunogenetics in rheumatology. Amsterdam: Excerpta Medica, 1982: 185-7.

5 Malaviya A N, Mehra N K, Adhar G C et al. HLA-B27 in patients with seronegative spondarthritides. J Rheumatol 1979; 6: 413-6.

6 Prakash S, Mehra N K, Bhargava S, Malaviya A N. HLA-B27 related 'unclassifiable' seronegative spondyloarthropathies. Ann Rheum Dis 1983; 42: 640-3.

7 Prakash S, Mehra N K, Bhargava S, Malaviya A N. Reiter's disease in North India: a clinical and immunogenetic study. Rheumatol Int in press.

8 Terasaki P I and McClelland J D. Microdroplet assay of human cytotoxins. Nature 1964; 204: 998.
9 Kellgren J H, Jeffrey M R, Ball J. The epidemiology of chronic rheumatism. Oxford: Blackwell, 1963; i: 326.

10 Bywaters E G L. Symmetrical joint involvement. Ann Rheum Dis 1975; 34: 376.

11 Wilkinson M and Bywaters E G L. Clinical features and course of ankylosing spondylitis as seen in a follow-up of 222 hospital referred cases. Ann Rheum Dis 1958; 17: 209-28.

12 Wright V, Moll J M H. Seronegative polyarthritis. Amsterdam: North Holland, 1976: 81-168.

13 Engleman E G, Engleman E P. Ankylosing spondylitis: recent advances in diagnosis and treatment. Med Clin North Am 1977; 61: $347-64$.

14 Calabro J J, Gordon R D, Miller K I. Bechterew's syndrome in children: diagnostic criteria. Scand J Rheumatol 1979; suppl 32: 45-6.

15 Ladd J R, Cassidy J T, Martell W. Juvenile ankylosing spondylitis. Arthritis Rheum 1971; 14: 579-90.

16 Ebringer R W, Cawdell D R, Cowling P, Ebringer A. Sequential studies in ankylosing spondylitis: association of Klebsiella pneumoniae and active disease. Ann Rheum Dis 1978; 37: 146.

17 Cruickshank R. Pathology of ankylosing spondylitis. Bull Rheum Dis 1960; 10: 211 .

18 Malaviya A N, Raina V, Mittal V Ket al. Glomerulonephritis in seronegative spondylarthritis syndrome. Arthritis Rheum 1981; 24: $751-2$

19 Prakash S, Bansal R, Rajagopalan P, Malaviya A N. Immunological studies in seronegative spondyloarthropathies. BrJ Rheumatol 1983; 22: 146-50.

20 Panayi G S, Slaney J, Williams B D. Circulating immune complexes in patients with ankylosing spondylitis. Ann Rheum Dis 1980; 39: 445-8.

\section{Book review}

The Clinical Management of Systemic Lupus Erythematosus. Edited by Peter H. Schur. Pp. 290. $\$ 39.50$. Grune and Stratton: New York, 1983.

This book has 17 authors, contributing between them 18 chapters over 280 pages. There are now several books available devoted to systemic lupus erythematosus. I believe this book is best regarded as aimed principally at trainees and those physicians who occasionally see and manage patients with lupus. It succeeds admirably in this role. Literature references are adequate and general, but the book is not a bibliography or research source. For the most part it is succinctly written and the chapters hang together well. There are clearly pragmatic sections such as that on clinical monitoring and the appendix on literature for the patient. The latter is relevant principally to the
American patient, and as yet the British SLE Aid Group does not have as comprehensive a literature.

The chapters are principally grouped to cover the manifestations of each system in turn: musculoskeletal. cutaneous, cardiopulmonary. etc. which makes it easy to seek a review of such manifestations. In addition, however, there are useful chapters on immunopathogenesis. diagnosis and serology, and haematological manifestations.

The authors are all well known in their field, and the book has been edited thoughtfully by Dr. Schur. A copy should be held in every undergraduate or postgraduate library, and many individual departments or clinicians may want to have their own copy. 